Kyong-Ah Yoon $\cdot$ Ja-Lok Ku $\cdot$ Han-Kwang Yang

Woo Ho Kim • Suk Young Park • Jae-Gahb Park

\title{
Germline mutations of E-cadherin gene in Korean familial gastric cancer patients
}

\begin{abstract}
Gastric cancer is the most common cancer in Korea. Germline mutations of the E-cadherin gene have recently been identified in familial gastric cancer patients. We screened five Korean familial gastric cancer patients to investigate germline mutations of the E-cadherin gene. These patients fulfilled the following criteria: presence of at least two gastric cancer patients within first-degree relatives and one patient diagnosed before the age of 50 years. Abnormal band patterns were found in exons 6 and 10 in two familial gastric cancer patients by polymerase chain reaction-single strand conformation polymorphism analysis (probands from the SNU-G2 and SNU-G1001 families, respectively). DNA sequencing analysis of the E-cadherin gene of these two patients revealed missense mutations in each exon. The SNU-G2 proband harbored a missense mutation from aspartic acid (GAT) to glycine (GGT) at codon 244 in exon 6 of the E-cadherin gene, and the SNU-G1001 proband had a missense mutation from valine (GTG) to alanine (GCG) at codon 487 in exon 10. The SNUG2 proband was diagnosed with gastric cancer at the age of 38; three brothers and two sisters had died of gastric cancer under the age of 50, and their mother had died of gastric cancer at the age of 63. The SNU-G1001 proband was diagnosed with gastric cancer at the age of 42 and one brother had died of gastric cancer at the age of 49. In summary, we found germline mutations of the E-cadherin gene in two of five Korean familial gastric cancer patients screened.
\end{abstract}

K.-A. Yoon $\cdot$ J.-L. Ku $\cdot$ J.-G. Park $(\bowtie)$

Laboratory of Cell Biology, Cancer Research Institute, Seoul

National University College of Medicine, 28 Yongon-dong,

Chongno-gu, Seoul 110-744, Korea

Tel. +82-2-760-3380; Fax +82-2-742-4727

E-mail: jgpark@plaza.snu.ac.kr

H.-K. Yang

Department of Surgery, Seoul National University College of Medicine, Seoul, Korea

W. H. Kim

Department of Pathology, Seoul National University College of Medicine, Seoul, Korea

S. Y. Park

Department of Internal Medicine, Taejon St. Mary's Hospital, College of Medicine, The Catholic University of Korea, Seoul, Korea
Key words Familial gastric cancer $\cdot$ E-cadherin $\cdot$ Germline · Mutation

\section{Introduction}

Gastric cancer is a major cause of cancer death worldwide, and is the most common form of cancer in Korea. Epidemiological studies have shown that some cases represent familial aggregation (La Vecchia et al. 1992). Since the carcinogenesis of gastric cancer has not been clearly defined, there is some doubt in regard to the inherited gene alterations and environmental factors shared by family members (Shinmura et al. 1998).

E (epithelial)-cadherin is a member of the family of transmembrane glycoproteins that are responsible for calcium-dependent cell-to-cell adhesion. It is reported that Ecadherin is inactivated by irreversible genetic alteration in carcinomas of gastric origin, and the expression of Ecadherin is reduced in $45.5 \%$ of cancers of various organs, including stomach cancer (Shiozaki et al. 1996).

Recently, germline mutations of the E-cadherin gene were identified in familial gastric cancer patients of three kindreds from New Zealand (Guilford et al. 1998); this represents a clear molecular basis for familial gastric cancer. Germline mutations of the E-cadherin gene were also reported in families of European origin, especially in a high proportion of diffuse-type gastric cancer patients (Gayther et al. 1998). We therefore screened for the presence of germline mutations of the E-cadherin gene in five Korean familial gastric cancer patients.

\section{Patients and Methods}

Patients

We collected blood samples from a total of five Korean gastric cancer patients who had been treated at Seoul National University Hospital. These patients fulfilled the fol- 
Table 1 Germline mutations of the E-cadherin gene in gastric cancer families

\begin{tabular}{|c|c|c|c|c|c|c|c|c|}
\hline Family & $\begin{array}{l}\text { No. of gastric } \\
\text { cancer patients }\end{array}$ & $\begin{array}{l}\text { Age (years) } \\
\text { mean(range) }\end{array}$ & $\begin{array}{l}\text { Age of } \\
\text { proband (year) }\end{array}$ & $\begin{array}{l}\text { Mutation o } \\
\text { Exon }\end{array}$ & $\begin{array}{l}\text { E-cadhe } \\
\text { codon }\end{array}$ & $\begin{array}{l}\text { gene in proba } \\
\text { n.t. change }\end{array}$ & $\begin{array}{l}\text { d } \\
\text { a.a. change }\end{array}$ & $\begin{array}{l}\text { Histologic } \\
\text { type }\end{array}$ \\
\hline SNU-G1 & 5 & $33(22-57)$ & 57 & Wild type & & & & Diffuse \\
\hline SNU-G2 & 7 & $42(30-63)$ & 38 & 6 & 244 & $\mathrm{GAT} \rightarrow \mathrm{GGT}$ & Asp $\rightarrow$ Gly & Diffuse \\
\hline SNU-G1001 & 2 & $46(42-49)$ & 42 & 10 & 487 & $\mathrm{GTG} \rightarrow \mathrm{GCG}$ & $\mathrm{Val} \rightarrow$ Ala & Diffuse \\
\hline SNU-G1003 & 2 & $36(26-45)$ & 26 & Wild type & & & & Diffuse \\
\hline SNU-G1005 & 3 & $46(33-56)$ & 33 & Wild type & & & & Diffuse \\
\hline
\end{tabular}

n.t., Nucleotide; a.a., aminoacid

lowing criteria: presence of at least two gastric cancer patients within first-degree relatives and at least one patient diagnosed before the age of 50 years. All five patients examined were diagnosed with diffuse-type gastric carcinoma. Mutational analysis of the E-cadherin gene was performed with DNA samples from all five patients. For a genetic polymorphism study, we screened DNA samples from peripheral blood lymphocytes of 50 healthy persons and normal colonic mucosa DNA of 50 colorectal cancer patients.

\section{DNA extraction}

Peripheral blood lymphocytes of the gastric cancer patients and healthy persons were isolated using Ficoll-Paque according to the manufacturer's instructions (Pharmacia Biotech, Uppsala, Sweden). Total genomic DNA was extracted using TRI reagent, also according to the manufacturer's instructions (Molecular Research Center, Cincinnati, OH, USA).

Polymerase chain reaction (PCR) amplification and single strand conformation polymorphism (SSCP) analysis

To investigate the genetic alteration of the E-cadherin gene, we screened 16 exons by PCR-SSCP in the five Korean gastric cancer patients. The PCR primer pairs were prepared as described by Berx et al. (1995a). Non-radioactive PCR reactions were carried out in a volume of $25 \mu \mathrm{l}$ containing $100 \mathrm{ng}$ genomic DNA, 2.5 pmoles of each primer, four dNTP at $250 \mu \mathrm{M}$ each, 0.5 units of Taq polymerase, and the reaction buffer provided by the supplier (Boehringer Mannheim, Mannheim, Germany). Reactions were initiated by denaturation for $5 \mathrm{~min}$ at $94^{\circ} \mathrm{C}$ and carried out for 35 cycles in a programmable thermal cycler (Perkin Elmer Cetus 9600; Roche Molecular Systems, Nutley, NJ, USA). PCR conditions consisted of 35 cycles of $94^{\circ} \mathrm{C}$ for $30 \mathrm{~s}$, 55$60^{\circ} \mathrm{C}$ for $1 \mathrm{~min}$, and $72^{\circ} \mathrm{C}$ for $1 \mathrm{~min}$, with a final elongation of $10 \mathrm{~min}$ at $72^{\circ} \mathrm{C}$.

For SSCP, the genomic DNA in each exon of the $E$ cadherin gene was amplified in a final volume of $10 \mu \mathrm{l}$, using the same PCR procedure as that described above, but with the addition of $\left[\alpha-{ }^{32} \mathrm{P}\right]-\mathrm{dCTP}$ (Amersham, Arlington Heights, IL, USA). The region from exons 4 to 5 was amplified in a single PCR. Radiolabeled PCR reaction products were mixed with $95 \%$ formamide dye, denatured at $94^{\circ} \mathrm{C}$ for $5 \mathrm{~min}$, and chilled on ice. Three microliters of mixture was loaded on a nondenaturing SSCP gel, $6 \%$ polyacrylamide (19:1) with $10 \%$ glycerol in $1 \times$ Tris Borate-EDTA (TBE) buffer, and separated for $12-16 \mathrm{~h}$ in a cold room (4 ${ }^{\circ} \mathrm{C}$ ) at a constant $300 \mathrm{~V}$. After electrophoresis, the gel was transferred to $3 \mathrm{MM}$ Whatman paper, dried on a gel dryer and sumitted to autoradiography.

\section{Cloning and sequencing}

Samples showing abnormal bands by SSCP were submitted to cloning for DNA sequencing analysis. Fresh PCR products were ligated into pCR-TOPO vectors (product of Invitrogen company) and subcloned using the TA cloning system (Invitrogen, San Diego, CA, USA). A minimum of ten individual colonies were taken and cultured overnight in Luria-Bertani (LB) medium containing $50 \mu \mathrm{g} / \mathrm{ml}$ ampicillin. Plasmid DNA was isolated and used for DNA sequencing analysis. Bidirectional sequencing analysis was performed using the Taq dideoxy terminator cycle sequencing kit on an ABI 377 DNA sequencer (Perkin-Elmer, Foster city, CA, USA). Sequences of target DNA were determined by using the original PCR primers.

\section{Results}

All five patients examined were affected by diffuse type gastric cancers (Table 1).

To investigate the germline mutation of the E-cadherin gene, we screened 16 exons by PCR-SSCP in five Korean familial gastric cancer patients. From our PCR-SSCP analysis, abnormal band patterns were found in probands SNU-G2 and SNU-G1001 of each family in exons 6 and 10, respectively. However, there were no abnormal bands in the other samples including the five unaffected members of the SNUG1 proband's family. DNA sequencing analysis of the $E$ cadherin gene in these two patients revealed missense mutations in each exon. The SNU-G2 proband harbored a missense mutation from aspartic acid (GAT) to glycine (GGT) at codon 244 in exon 6 of the E-cadherin gene (Fig. 1 and Fig. 2). The SNU-G1001 proband had a missense mutation from valine (GTG) to alanine (GCG) at codon 487 in exon 10. Reliability of the analyses was confirmed by PCRSSCP in the 50 blood DNA samples of non-cancer patients and the 50 normal colonic mucosa DNA samples of colorectal cancer patients. The SNU-G2 proband was diag- 
Fig. 1. Pedigree of SNU-G2 familial gastric cancer family. Individuals' ages are indicated to the right of the symbols. Symbols, squares, males; circles, females; all symbols with a diagonal, deceased; $\mathrm{Ca}$, Cancer

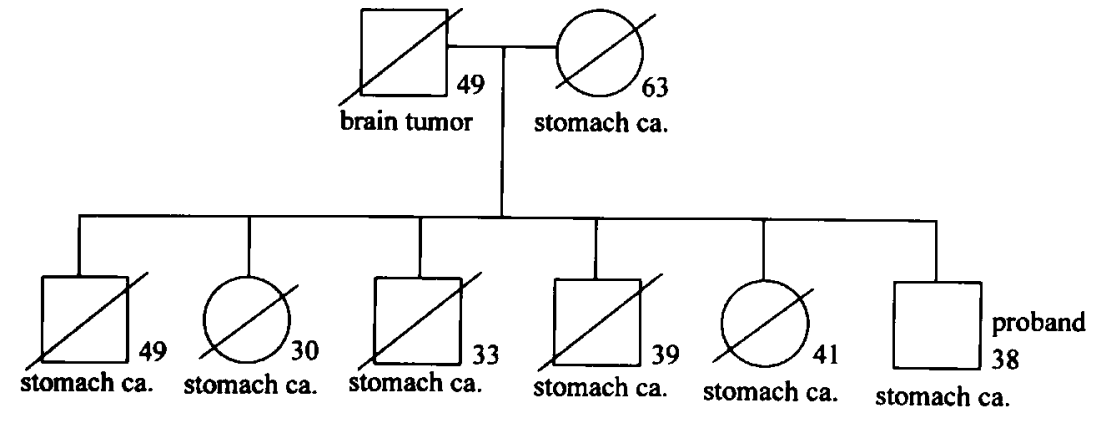

Fig. 2. Germline mutation of exon 6 in the E-cadherin gene of proband SNU-G2. As a result of polymerase chain reaction-single-strand conformation polymorphism (PCR$S S C P$ ) analysis, abnormal band patterns were found in exon 6 of the SNU-G2 proband. Lane numbers (1-5) indicate each proband are; lane 1, SNU-G1; lane 2, SNUG1001; lane 3, SNU-G2; lane 4, SNU-G1003; lane 5, SNU-G1005. DNA sequencing analysis of exon 6 of the $E$ cadherin gene revealed a missense mutation from aspartic acid (GAT) to glycine (GGT) at codon 244

\section{PCR-SSCP exon 6}

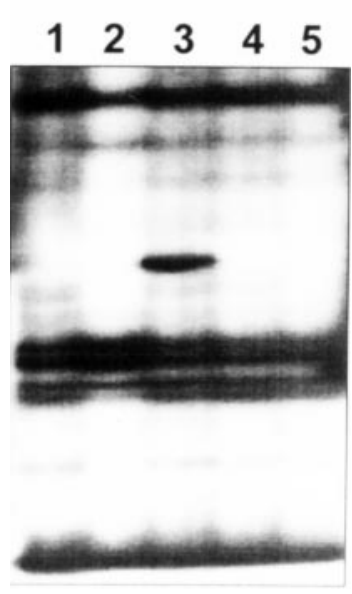

DNA Sequencing Analysis (SNU-G2)

Wild Type

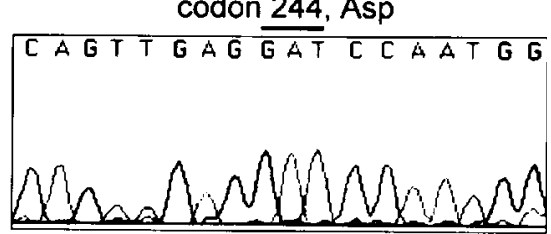

Mutant Type

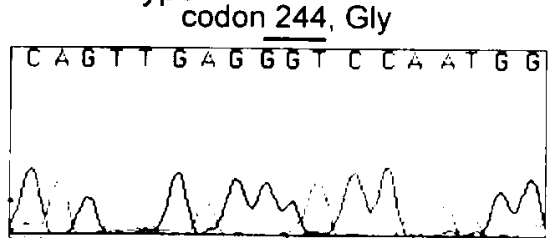

nosed with gastric cancer at the age of 38 and his mother had died of gastric cancer at the age of 63 (Fig. 1). The SNUG1001 proband was diagnosed with gastric cancer at the age of 42 and one brother had died of gastric cancer at the age of 49 .

\section{Discussion}

The role of the E-cadherin gene in the tumorigenesis of gastric cancer has been established previously with somatic mutations in diffuse type gastric cancers (reviewed by Gayther et al. 1998). Becker et al. (1994) provided strong invivo evidence that $E$-cadherin gene mutations may contribute to the development of diffusely growing gastric carcinomas. Moreover, germline mutations of the $E$ cadherin gene have only been reported in familial gastric cancer patients with diffuse type gastric cancers (Guilford et al. 1998; Gayther et al. 1998). All five patients we examined were diagnosed with diffuse type gastric cancer.

We screened germline mutations of the E-cadherin gene in five Korean familial gastric cancer patients by PCR-SSCP and sequencing analysis. Missense germline mutations of the E-cadherin gene were detected in two patients. These two patients with germline mutations had been diagnosed with gastric cancer at the ages of 38 and 42, respectively, and both patients had a family history of gastric cancers.

Missense mutation of the E-cadherin gene is relatively rare compared with other types of mutation, including frameshift mutation (reviewed by Berx et al. 1998). Six truncating mutations and one missense mutation in the germline in familial gastric cancer patients have been reported in the literature (Guilford et al. 1998; Gayther et al. 1998). To date, only 11 missense mutations have been reported in various cancers. Of these, one was a germline mutation and the rest were somatic mutations. Moreover, 6 of these 11 missense mutations were identified in gastric cancers (reviewed by Berx et al. 1998). Our data showed two germline mutations at exons 6 and 10, respectively. To date, a total of 18 polymorphism sequence variants have been identified (reviewed by Berx et al. 1998). The two missense mutations identified in our study did not belong to these polymorphisms. Since these nucleotide changes were not detected in the 100 normal control DNA samples at exons 6 and 10, it is likely that these variants are germline mutations rather than genetic polymorphism. In addition, the two missense mutations occurred in highly conserved amino acid residues (Berx et al. 1995b) belonging to extracellular domains in $\mathrm{Ca}^{2+}$-binding motifs, although the effect of these mutations on protein function should still be examined. In summary, we have presented 
the identification and characterization of germline mutations of the $E$-cadherin gene in two of five Korean familial gastric cancer patients.

Acknowledgments This work was supported in part by a grant from the Korea Science and Engineering Foundation (KOSEF) through the Cancer Research Center at Seoul National University (KOSEF-CRC-97-8).

\section{References}

Becker K-F, Atkinson MJ, Reich U, Becker I, Nekarda H, Siewert JR, Höfler H (1994) E-cadherin gene mutations provide clues to diffuse type gastric carcinomas. Cancer Res 54: 3845-3852

Berx G, Becker KF, Höfler H, van Roy F (1998) Mutations of the human E-cadherin (CDH1) gene. Hum Mutation 12: 226-237

Berx G, Cleton-Jansen AM, Nollet F, de Leeuw WJF, van de Vijver MJ, Cornelisse C, van Roy F (1995a) E-cadherin is a tumour/inva- sion suppressor gene mutated in human lobular breast cancers. EMBO J 14: 6107-6115

Berx G, Staes K, van Hengel J, Molemans F, Bussemakers MJG, van Bokhoven A, van Roy F (1995b) Cloning and characterization of the human invasion suppressor gene E-cadherin (CDH1). Genomics 26: 281-289

Gayther SA, Gorringe KL, Ramus SJ, Huntsman D, Roviello F, Grehan N, Machado JC, Pinto E, Seruca R, Halling K, MacLeod P, Powell SM, Jackson CE, Ponder BAJ, Caldas C (1998) Identification of germ-line E-cadherin mutations in gastric cancer families of European origin. Cancer Res 58: 4086-4089

Guilford P, Hopkins J, Harraway J, McLeod M, McLeod N, Harawira P, Taite H, Scoular R, Miller A, Reeve AE (1998) E-cadherin germline mutations in familial gastric cancer. Nature 392:402-405

La Vecchia C, Negri E, Franceschi S, Gentile A (1992) Family history and the risk of stomach and colorectal cancer. Cancer 70: 50-55

Shinmura K, Tani M, Isogaki J, Wang Y, Sugimura H, Yokota J (1998) RER phenotype and its associated mutations in familial gastric cancer. Carcinogenesis 19: 247-251

Shiozaki H, Oka H, Inoue M, Tamura S, Monden M (1996) E-cadherin mediated adhesion system in cancer cells. Cancer 77: 1605-1613 